\title{
Tingkat Kesukaan Konsumen Terhadap Serat Kenaf Organik dengan Pewarna Alami
}

\section{Consumer Success Level of Organic Kenaf Fiber With Natural Dyes}

\author{
Rusmini ${ }^{1}$, Dwinita Aquastini ${ }^{1}$, Riama Rita Manullang ${ }^{1}$ dan Daryono ${ }^{1}$ \\ ${ }^{1}$ State Agricultural Polytechnic Institute of Samarinda \\ *E-mail : iefira07@gmail.com
}

\begin{abstract}
Production of kenaf fiber for industry mostly uses chemical fertilizers with synthetic dyes that will also cause health and environmental problems and adversely affect all life forms. Increased health and environmental concern make organic kenaf fiber production with natural dyes highly recommended for both handicrafts and for industrial scale because natural fertilizers and dyes are non-toxic, decomposable, and environmentally friendly. The purpose of this study is to determine the level of consumer preference to organic kenaf fiber with natural dyes. The study used a two-factor group randomized design with the first factor of organic kenaf fiber and a second factor of natural dye consisting of 3 levels. The research was repeated as many as 2 replications so that there were 6 experimental units. Variables observed by consumer's level of craft product from organic kenaf fiber with natural dye covering color, texture and odor tested. This test is done by Hedonic Test method, using questionnaire with untrained panelist (consumer) as many as 40 people with data obtained based on a panelist response using a hedonic scale was analyzed by Kruskal-Wallis test. The results showed that there was no significant difference in consumer preferences for the color, texture and odor of organic kenaf fiber with various natural dyes.
\end{abstract}

Keywords: kenaf, turmeric, suji leaves, and dragon fruit skin

Disubmit : 11 Agustus 2018; Diterima: 12 Oktober 2018; Disetujui : 04 Januari 2019;

\section{PENDAHULUAN}

Kenaf adalah jenis tanaman yang mudah dibudidayakan di daerah tropis seperti Indonesia. Kenaf sangat potensial untuk industri secara global karena kandungan selulosanya tinggi. Kandungan serat alam umumnya terdiri dari selulosa, hemiselulosa, dan lignin. Selulosa dari serat alam memiliki struktur yang tersusun dalam micro-fibrils dilingkupi oleh dua komponen utama, yaitu : hemiselulosa dan lignin. Serat kenaf organik yang memiliki kandungan holosellulosa pada serat kenaf yang terbaik yaitu 81,2800\% dan kandungan sellulosa yang terbaik yaitu 40,5695\% (Rusmini, R.R.Manullang, 2017). Serat kenaf organik merupakan serat kenaf yang dihasilkan dari batang tanaman kenaf yang sudah melalui berbagai tahapan baik dari segi pemupukan dan pengendalian hama yang dilakukan secara organik maupun dalam hal kegiatan penyeratan, umumnya serat kenaf berwarna putih kekuningan dan digunakan sebagai bahan baku dalam produk diversifikasi, seperti : kertas, pelapis dinding, interior mobil, geotekstil, soil safer, fiber drain, particle board, dan reinforcement plastik serta bahan baku industri biofuel. Proses pewarnaan diperlukan untuk membuat tampilan serat kenaf organik menjadi lebih menarik bagi konsumen dan berdaya jual tinggi. Bahan pewarna sintetik biasa digunakan dalam pewarnaan serat karena lebih mudah dalam penggunaanya. 
Pewarna sintetis mempunyai beberapa keunggulan dibandingkan dengan zat pewarna alam yaitu antara lain, mudah diperoleh di pasar, ketersediaan warna terjamin, jenis warna beragam dan lebih praktis serta lebih mudah digunakan (Kartina, B., T. Ashar, 2013) serta lebih ekonomis (Purnomo, 2004) dan lebih murah (Paryanto, A. Purwanto, E. Kwartiningsih, 2012); (Kartina, B., T. Ashar, 2013). Di samping itu pewarna sintetis, lebih stabil, lebih tahan terhadap berbagai kondisi lingkungan, daya mewarnainya lebih kuat dan memiliki rentang warna yang dapat terdegradasi menjadi senyawa yang bersifat karsinogenik dan beracun industri tekstil penuh warna dan bahan kimia organik dari zat pewarna sintetis. Bercampurnya material koloid dengan limbah pewarna, dapat meningkatkan kekeruhan dan menjadikan air berpenampilan buruk, berbau, mencegah penetrasi sinar matahari. Di samping itu ketika limbah dibiarkan mengalir akan menyumbat pori -pori tanah yang berakibat pada hilangnya produktivitas tanah, tekstur tanah mengeras dan mencegah penetrasi akar tumbuhan (Kant, 2012).

Pewarna alami merupakan alternatif pewarna yang tidak toksik, dapat diperbaharui (renewable), mudah terdegradasi dan ramah lingkungan. Keunggulan penggunaan zat warna alam adalah karena memiliki nilai ekonomi dan nilai jual yang tinggi dan ramah lingkungan. Warna-warna tekstil yang menggunakan warna alam lebih khas dan lembut dibandingkan dengan warna sintetik sehingga mempunyai nilai estetika yang tinggi. Meskipun penggunaan zat warna alam mempunyai beberapa kelemahan dibandingkan dengan zat warna sintetis, namun masih terus digunakan hingga saat ini. Zat warna alam telah direkomendasikan sebagai pewarna yang ramah baik bagi lingkungan maupun kesehatan karena kandungan komponen alaminya mempunyai nilai beban pencemaran yang relatif rendah, mudah terdegradasi secara biologis dan tidak beracun (Rungruangkitkrai, 2012).

Tumbuhan yang digunakan sebagai pewarna dapat diperoleh di sekitar lingkungan kita sehingga hemat biaya. Keunggulan dari zat warna alam antara lain, warna yang dihasilkan sangat variatif dan unik, warna cenderung kearah soft, intensitas warna terhadap kornea mata terasa sangat menyejukkan sehingga akan menyehatkan mata, dan mengandung antioksidan sehingga nyaman dan aman apabila dipakai oleh manusia. Rancangan busana yang menggunakan zat warna alam memiliki nilai jual atau nilai ekonomi yang tinggi karena memiliki nilai seni dan warna khas, ramah lingkungan sehingga berkesan etnik dan eksklusif.

Sebagai upaya mengangkat kembali penggunaan zat warna alam untuk tekstil maka diperlukan sumber zat warna dari potensi sumber daya alam lokal yang ada, ketersediaannya kontinyu dan berkesinambungan, produksi bahan baku stabil, dan bukan produk musiman, antara lain adalah daun suji, kunyit dan kulit buah naga. Dengan demikian peneliti tertarik untuk meneliti penggunaan pewarna alami terhadap serat kenaf organik terhadap tingkat kesukaan konsumen.

\section{METODE PENELITIAN}

Penelitian dilaksanakan di Laboratorium produksi dan kimia analisis tanaman kehutanan Politeknik Pertanian Negeri Samarinda dari bulan Februari sampai dengan Mei 2018. Alat yang digunakan toples ukuran 10 l, pisau, talenan, gunting, timbangan, blender dan saringan kain, corong kaca, gelas ukur, tumbukan dari batu, parutan kelapa dan pengaduk sedangkan bahan yang digunakan serat kenaf organik sebanyak $4 \mathrm{~kg}$, daun suji, kunyit,dan kulit buah naga, kertas saring, tali rafia dan air.

\section{Rancangan Percobaan}

Percobaan ini merupakan penelitian faktorial terdiri dari 2 faktor, dilaksanakan dengan menggunakan Rancangan Acak Kelompok. Faktor pertama kompos yang terbaik pada tahun 2017 dari kulit udang + pesnab ( K) yang terdiri dari 1 taraf yaitu:

$\mathrm{k}_{1} \quad=$ Pemberian kompos sebanyak 30 ton $\mathrm{ha}^{-1}$ atau $3 \mathrm{~kg} /$ petak dan pemberian pestisida nabati sebanyak $100 \mathrm{ml} /$ tanaman. Faktor kedua adalah pewarna alami terdiri dari 3 taraf yaitu :

$\mathrm{p}_{1}=$ Daun Suji 
$\mathrm{p}_{2}=$ Kunyit

$\mathrm{p}_{3}=$ Kulit buah naga

Masing-masing penelitian diulang sebanyak 2 ulangan sehingga terdapat 6 satuan percobaan.

\section{Pembuatan Ekstrak Pewarna Alami}

Proses pembuatan ekstrak pewarna alami mengacu pada (Pringgenies, D., E. Supriyantini, R. Azizah, 2012) dan telah dilakukan modifikasi.

\section{Pembuatan Ekstrak Pewarna Alami Daun Suji}

Daun suji yang segar dipotong kecil-kecil dengan gunting kemudian ditimbang masing-masing sebanyak $4 \mathrm{~kg}$ kemudian dicuci bersih, selanjutnya daun suji ditumbuk untuk mengecikan ukurannnya kemudian diblender secara bertahap dengan pengenceran sebanyak 51 untuk $1 \mathrm{~kg}$ daun suji sehingga total air yang ditambahkan sebanyak 201 kemudian disaring dengan saringan kain dilanjutkan dengan menggunakan kertas saring agar larutan pewarna benar-benar homogen, untuk ulangan 1 dan untuk ulangan 2 dilakukan seperti ulangan 1 selanjutnya keduanya masing-masing dmasukkan ke dalam toples sebagai pewarna daun suji untuk ulangan 1 dan 2.

\section{Pembuatan Ekstrak Pewarna Alami Kunyit}

Kunyit dikupas sampai bersih kemudian ditimbang sebanyak $4 \mathrm{~kg}$, selanjutnya dicuci sampai bersih kemudian kunyit yang sudah bersih diparut dengan menggunakan parutan kelapa sampai benar-benar halus, selanjutnya baru dimasukkan air sebanyak 201 secara bertahap kemudian disaring dengan saringan kain dilanjutkan dengan menggunakan kertas saring agar larutan pewarna benar-benar homogen, untuk ulangan 1 dan untuk ulangan 2 dilakukan seperti ulangan 1 selanjutnya keduanya masing-masing dmasukkan ke dalam toples sebagai pewarna daun suji untuk ulangan 1 dan 2.

\section{Pembuatan Ekstrak Pewarna Alami Kulit Buah Naga}

Buah naga dikupas sampai bersih kemudian kulitnya ditimbang sebanyak $4 \mathrm{~kg}$, selanjutnya dicuci sampai bersih kemudian kulit buah naga yang sudah bersih dipotong kecil-kecil dengan gunting selanjutnya baru diblender secara bertahap dengan dimasukkan air yang diambil dari air sebanyak 201 secara bertahap kemudian disaring dengan saringan kain dilanjutkan dengan menggunakan kertas saring agar larutan pewarna benar-benar homogen, untuk ulangan 1 dan untuk ulangan 2 dilakukan seperti ulangan 1 selanjutnya keduanya masing-masing dmasukkan ke dalam toples sebagai pewarna daun suji untuk ulangan 1 dan 2 .

\section{Perendaman serat kenaf organik dengan pewarna daun suji}

Serat kenaf organik ditimbang sebanyak $1 \mathrm{~kg}$ untuk ulangan 1 dan $1 \mathrm{~kg}$ juga untuk ulangan 2, kemudian serat kenaf organik direndam di dalam pewarna alami daun suji yang sudah dimasukan ke dalam toples. Untuk menghindari serat kenaf timbul kepermukaan/tidak terendam maka diberi pemberat berupa batu yang sudah dibersihkan yang diberi plastik warna putih untuk menjaga agar plastik tidak mempengaruhi hasil rendaman. Kemudian toples ditutup rapat selama 3 hari.

\section{Perendaman serat kenaf organik dengan pewarna kunyit}

Serat kenaf organik ditimbang sebanyak $1 \mathrm{~kg}$ untuk ulangan 1 dan $1 \mathrm{~kg}$ juga untuk ulangan 2, kemudian serat kenaf organik direndam di dalam pewarna alami daun suji yang sudah dimasukan ke dalam toples. Untuk menghindari serat kenaf timbul kepermukaan/tidak terendam maka diberi pemberat berupa batu yang sudah dibersihkan yang diberi plastik warna putih untuk menjaga agar plastik tidak mempengaruhi hasil rendaman. Kemudian toples ditutup rapat selama 3 hari. 


\section{Perendaman serat kenaf organik dengan pewarna kulit buah naga}

Serat kenaf organik ditimbang sebanyak $1 \mathrm{~kg}$ untuk ulangan 1 dan $1 \mathrm{~kg}$ juga untuk ulangan 2, kemudian serat kenaf organik direndam di dalam pewarna alami daun suji yang sudah dimasukan ke dalam toples. Untuk menghindari serat kenaf timbul kepermukaan/tidak terendam maka diberi pemberat berupa batu yang sudah dibersihkan yang diberi plastik warna putih untuk menjaga agar plastik tidak mempengaruhi hasil rendaman. Kemudian toples ditutup rapat selama 3 hari.

\section{Pengeringan Serat Kenaf}

Setelah proses perendaman selama 3 hari, maka serat kenaf organik yang direndam dengan pewarna alami sesuai perlakuan langsung diangkat dan ditiriskan, selanjutnya serat kenaf organik dikat dengan tali rafia untuk digantung dan dikeringkan selama 10 hari di dalam ruangan tanpa terkena sinar matahari un menghindari pengaruh sinar ultra violet dari sinar matahari.

\section{Pengamatan}

Parameter yang diamati meliputi tingkat kesukaan konsumen terhadap produk kerajinan dari serat kenaf organik dengan pewarna alami yang meliputi warna, tekstur dan bau dari produk serat yang diuji. Uji ini dilakukan dengan metode Hedonic Test, menggunakan kuisoner dengan panelis tidak terlatih (konsumen) sebanyak 40 orang.

\section{Analisa Data}

Data diuji dengan metode Hedonic Test, menggunakan kuisoner dengan panelis tidak terlatih (konsumen) sebanyak 40 orang. Data yang diperoleh berdasarkan respon panelis dengan menggunakan skala hedonik dianalisis dengan uji Kruskal-Wallis. Kuisioner dengan skala penilaian sangat suka :7, suka : 6, agak suka: 5, netral/biasa : 4, agak tidak suka: 3 , tidak suka: 2 dan sangat tidak suka : 1

\section{HASIL DAN PEMBAHASAN}

\section{Organoleptik Tingkat Kesukaan Terhadap Warna, Tekstur dan Aroma Warna}

Warna adalah persepsi yang muncul dalam otak manusia saat melihat refleksi dari cahaya pada suatu objek. Warna dipengaruhi oleh komposisi fisik dan kimia suatu objek, cahaya yang dipantulkan, serta sensitivitas mata seseorang (Lawless, T. Harry, 2010). Warna merupakan salah satu daya tarik utama, dan menjadi kriteria penting untuk penerimaan produk seperti tekstil, kosmetik, pangan dan lainnya. Zat warna sangat diperlukan untuk menambah nilai artistik dan digunakan dalam mem-variasikan suatu produk (Jos, B., P.E. Setyawan, 2011)

Warna merupakan kesan pertama yang ditangkap panelis sebelum mengenali rangsangan-rangsangan yang lain. Warna sangat penting bagi setiap produk sehingga warna yang menarik akan mempengaruhi penerimaan konsumen. Berdasarkan hasil analisis Kruskal-Wallis terhadap tingkat kesukaan konsumen pada warna menunjukkan pengaruh yang tidak berbeda nyata. Tabel nilai rata-rata tingkat kesukaan konsumen terhadap warna serat kenaf organik dapat dilihat pada Tabel 1.

Tabel 1. Nilai rata-rata tingkat kesukaan konsumen terhadap warna serat kenaf organik

\begin{tabular}{clll}
\hline \multirow{2}{*}{$\begin{array}{c}\text { Serat kenaf organik } \\
(\mathrm{K})\end{array}$} & \multicolumn{3}{c}{ Pewarna Alami } \\
\cline { 2 - 4 } & Daun suji $\left(\mathrm{p}_{1}\right)$ & Kunyit $\left(\mathrm{p}_{2}\right)$ & Kulit Buah Naga $\left(\mathrm{p}_{3}\right)$ \\
\hline $\mathrm{K}_{1}$ & 5.46 & 5.10 & 5.16 \\
\hline
\end{tabular}


Pengamatan dari hasil kuisioner dapat dilihat warna rata-rata yang paling tinggi daun suji dengan 5,46 (termasuk skala nilai agak suka) sedangkan yang pada kunyit nilai 5.10 (termasuk skala nilai agak suka) serta kulit buah naga dengan nilai 5.16. Meski tidak berbeda nyata dengan yang lain. Berdasarkan uji organoleptik dengan menggunakan analisis Kruskal-Wallis terhadap tingkat kesukaan konsumen pada warna menunjukkan bahwa pewarna alami (daun suji, kunyit dan kulit buah naga tidak berpengaruh nyata terhadap tingkat kesukaan konsumen. Hal ini berarti, setiap jenis pewarna alami memberikan pengaruh yang sama terhadap kesukaan setiap orang akan warna serat kenaf organik.

Tidak terdapat perbedaan yang signifikan antara faktor pertama yaitu kombinasi antara (pemberian kompos dan pemberian pestisida) dengan faktor kedua yaitu pewarna alami daun suji, kunyit dan kulit buah naga terhadap warna serat kenaf akan tetapi dari hasil kuisioner menunjukkan bahwa rata-rata panelis agak suka (5) bahkan mendekati suka dengan ketiga pewarna alami. Hal ini menunjukkan bahwa panelis agak menyukai pewarna alami pada serat kenaf organik meskipun tidak menggunakan mordan sebagai bahan untuk meningkatkan kecerahan warna karena peneliti menginginkan semuanya benar-benar alami atau organik. Hal ini sejalan dengan penelitian (Adejumo, A.L, F.A Aderibigbe, 2013) yang menyatakan bahwa rata-rata tingkat kesukaan konsumen menyukai pewarna alami daun sirsak pada kain Mori dan didukung juga dengan penelitian pewarna alami daun mangrove Rhizophora mucronata disukai oleh konsumen (46,67 \%) pada kain batik (Hidayati D.P.A., D Pringgenies, 2018).

Warna serat kenaf organik secara statistik tidak berbeda hal ini karena dalam uji organoleptik pewarna alami relatif sama sehingga panelis tidak bisa membedakan warna serat kenaf organik tersebut. Hal ini diduga karena panelis tidak begitu mengenal serat kenaf organik dengan pewarna alami dibandingan dengan pewarna sintetis hal ini sejalan dengan penelitian uji organoleptik warna dengan fiksator tawas dan kapur tohor menunjukkan hasil yang tidak berpengaruh nyata terhadap pewarna alami dari daun papaya (Pranoto, D., M. Purwanto, A. Widiawati, 2017). Hasil penelitian ini berbeda dengan penelitian (Anzani, S. D., Wignyanto, M. H. Pulungan, 2016) yang menyatakan bahwa pewarna alami dengan daun sirsak dengan mordan atau fiksator tawas menunjukkan hasil berbeda nyata dengan fiksator yang lain dengan fiksator yang terbaik adalah fiksator tawas.

Warna yang dihasilkan dari pewarna alami daun suji, kunyit dan kulit buah naga termasuk dalam kategori sedang secara visual karena dalam penelitian ini tidak menggunakan mordan yang memiliki fungsi sebagai pembangkit warna pada pewarnaan kain dengan pewarna alam. Hal ini sejalan dengan penelitian Prastyaningtyas (2014) hasil penelitinnya yang mencelup kain shantung dengan pewarna ekstrak daun sirsak dan rimpang kunyit tanpa menggunakan mordan juga menghasilkan warna dengan kategori sedang. Penggunaan mordan juga dapat menambah gugus khromofor dalam serat yang menyebabkan ketuaan warna hasil celup akan lebih tua jika dibandingkan dengan hasil celup kain tanpa menggunakan mordan. Hal ini didukung juga dengan penelitian Zheng et.al., (2011) yang menyatakan bahwa membuktikan bahwa tanah akan dapat menjadi mordan alami yang ramah lingkungan dalam pencelupan alami kain rami sedangkan Pawar, et. al (2017) menyatakan bahwa modifikasi kimia pewarna alami dari biji pinang dapat digunakan untuk mengatasi keterbatasan pewarna alami seperti miskin kekuatan, kurangnya reproduktifitas karena kemurnian yang bervariasi dan sifat tahan luntur inferior untuk skala besar aplikasi tanpa adanya mordan.

\section{Tekstur}

Tekstur atau tingkat kehalusan merupakan hal yang juga penting dalam serat atau kain. Berdasarkan hasil analisis Kruskal-Wallis terhadap tingkat kesukaan konsumen pada tekstur menunjukkan pengaruh yang tidak berbeda nyata. Tabel rata-rata tingkat kesukaan konsumen terhadap tekstur serat kenaf organik dapat dilihat pada Tabel 2 berikut ini: 
Rusmini, dkk; Tingkat Kesukaan Konsumen Terhadap Serat Kenaf Organik dengan Pewarna Alami

Tabel 2. Nilai rata-rata tingkat kesukaan konsumen terhadap tekstur serat kenaf organik
Serat kenaf organik
Pewarna Alami

$(\mathrm{K})$

\begin{tabular}{cccc}
\cline { 2 - 4 } & Daun suji $\left(\mathrm{p}_{1}\right)$ & Kunyit $\left(\mathrm{p}_{2}\right)$ & Kulit Buah Naga $\left(\mathrm{p}_{3}\right)$ \\
$\mathrm{K}_{1}$ & 4.51 & 4.28 & 4.55
\end{tabular}

Tidak terdapat perbedaan yang signifikan antara faktor pertama yaitu kombinasi antara (pemberian kompos dan pemberian pestisida) dengan faktor kedua pewarna alami yaitu pewarna dari daun suji, kunyit dan kulit buah naga terhadap tekstur serat kenaf. Berdasarkan hasil analisis yang telah didapat dari segi tekstur serat kenaf, tidak terdapat perbedaan tingkat kesukaan konsumen antara kombinasi faktor pertama (pemberian kompos dan pemberian pestisida) dengan faktor kedua pewarna alami (daun suji, kunyit dan kulit buah naga). Hal ini berarti, setiap jenis pewarna alami memberikan pengaruh yang sama terhadap kesukaan setiap orang akan tekstur serat kenaf organik dengan pewarna alami.

Tidak terdapat perbedaan yang signifikan antara faktor pertama yaitu kombinasi antara (pemberian kompos dan pemberian pestisida) dengan faktor kedua yaitu pewarna alami (daun suji, kunyit dan kulit buah naga) terhadap tekstur serat kenaf akan tetapi Tabel 2 menunjukkan bahwa rata-rata panelis bersifat netral/biasa (4) terhadap tekstur serat kenaf oranik yang diberi pewarna alami.

Tekstur serat kenaf organik dengan pewarna alami secara statistik tidak berbeda hal ini karena dalam uji organoleptik pewarna alami terhadap tekstur serat kenaf organik relatif sama sehingga panelis tidak bisa membedakan tekstur serat kenaf organik tersebut. Hal ini diduga karena panelis tidak begitu mengenal tekstur serat kenaf organik dengan pewarna alami dibandingan dengan pewarna sintetis dan jenis serat yang lainnya seperti kain batik, kain mori dan linen. Hal ini sejalan dengan penelitian (Pranoto, D., M. Purwanto, A. Widiawati, 2017) yang menyatakan bahwa uji organoleptik tingkat kehalusan/tekstur dengan fiksator tawas dan kapur tohor menunjukkan hasil yang tidak berpengaruh nyata terhadap pewarna alami dari daun papaya.

\section{Bau}

Bau adalah salah satu faktor yang menentukan kesukaan seseorang terhadap suatu makanan. Bau dapat memberikan persepsi suatu rasa tertentu pada suatu makanan (Kartika, 1988). Bau dijadikan salah satu standar uji pada serat kenaf organik yang diwarnai dengan pewarna alami karena bau yang dtimbukan dari pewarna alami mempunyai bau yang khas dari masing-masing bahan pewarna alami.

Berdasarkan hasil analisis Kruskal-Wallis terhadap tingkat kesukaan konsumen pada bau menunjukkan pengaruh yang tidak berbeda nyata. Tabel rata-rata tingkat kesukaan konsumen terhadap bau serat kenaf organik dapat dilihat pada Tabel 3.

Tabel 3. Nilai rata-rata tingkat kesukaan konsumen terhadap bau serat kenaf organik

\begin{tabular}{clll}
\hline \multirow{2}{*}{$\begin{array}{c}\text { Serat kenaf organik } \\
(\mathrm{K})\end{array}$} & \multicolumn{3}{c}{ Pewarna Alami } \\
\cline { 2 - 4 } & Daun suji $\left(\mathrm{p}_{1}\right)$ & Kunyit $\left(\mathrm{p}_{2}\right)$ & Kulit Buah Naga $\left(\mathrm{p}_{3}\right)$ \\
\hline $\mathrm{K}_{1}$ & 4.29 & 4.59 & 4.28
\end{tabular}

Tidak terdapat perbedaan yang signifikan antara faktor pertama yaitu kombinasi antara (pemberian kompos dan pemberian pestisida) dengan faktor kedua yaitu pewarna alami (daun suji, kunyit dan kulit buah naga) terhadap bau serat kenaf. Berdasarkan hasil analisis yang telah didapat dari segi bau serat kenaf, tidak terdapat perbedaan tingkat kesukaan konsumen antara kombinasi faktor pertama (pemberian kompos dan 
pemberian pestisida) dengan faktor kedua (pewarna alami daun suji, kunyit dan kulit buah naga). Hal ini berarti, setiap jenis pewarna alami memberikan pengaruh yang sama terhadap kesukaan setiap orang akan bau serat kenaf organik dengan pewarna alami daun suji, kunyit dan kulit buah naga.

Tabel 3 menunjukkan bahwa menunjukkan bahwa rata-rata panelis bersifat netral/biasa (4) terhadap bau serat kenaf oranik yang diberi pewarna alami. Bau serat kenaf organik dengan pewarna alami secara statistik tidak berbeda hal ini karena dalam uji organoleptik pewarna alami terhadap bau serat kenaf organik relatif sama sehingga panelis tidak bisa membedakan bau serat kenaf organik tersebut. Hal ini diduga karena panelis tidak begitu mengenal bau serat kenaf organik dengan pewarna alami daun suji, kunyit, dan kulit buah naga dibandingan dengan pewarna sintetis dan jenis serat yang lainnya seperti kain shantung, mori dan batik serta linen. Hal ini sejalan dengan penelitian (Pranoto, D., M. Purwanto, A. Widiawati, 2017) yang menyatakan bahwa uji organoleptik bau dengan fiksator tawas dan kapur tohor menunjukkan hasil yang tidak berpengaruh nyata terhadap pewarna alami dari daun papaya pada kain linen.

\section{KESIMPULAN}

Hasil penelitian menunjukkan bahwa tidak terdapat perbedaan yang nyata tingkat kesukaan konsumen terhadap warna, tekstur dan bau dari serat kenaf organik dengan berbagai pewarna alami daun suji, kunyit dan kulit buah naga tetapi dari hasil rata tingkat kesukaan konsumen menyatakan bahwa panelis rata-rata agak menyukai warna ,dan bersifat netral terhadap tekstur dan bau dari serat kenaf organik dengan pewarna alami daun suji, kunyit dan kulit buah naga.

\section{UCAPAN TERIMA KASIH}

Ucapan terima kasih disampaikan kepada Kementerian Riset, Teknologi, dan Pendidikan Tinggi yang telah memberikan dana untuk penelitian Strategis Nasional Institusi pada tahun 2017 no kontrak 05/PL.21/PL 2017 dan tahun 2018 dengan no kontrak 38/PL.21. C/PL/2018. Terima kasih juga disampaikan kepada Ketua Unit P2M Politeknik Pertanian Negeri Samarinda serta semua pihak yang telah membantu terlaksananya penelitian ini.

\section{DAFTAR PUSTAKA}

Adejumo, A.L, F.A Aderibigbe, R. U. O. R. (2013) 'Comparative studies of starch susceptibilities to $\alpha$ amylase degradation of different cereal and root crops of Nigeria', J. Biotechnol, 12(29), pp. 46634669.

Anzani, S. D., Wignyanto, M. H. Pulungan, dan S. R. L. (2016) 'Pewarna Alami Daun Sirsak (Annona muricata L.) untuk Kain Mori Primissima (Kajian: Jenis dan Konsentrasi Fiksasi)', Jurnal Teknologi dan Manajemen Agroindustri, 5(3), pp. 132-139.

Hidayati D.P.A., D Pringgenies, D. W. (2018) Pemanfaatan limbah daun dan kulit mangrove (rhizophora mucronata) sebagai bahan pewarna alami pada kain batik di Pesisir Semarang, eprints.undip.ac.id.

Jos, B., P.E. Setyawan, dan Y. S. (2011) 'Optimasi Ekstraksi dan Uji Stabilitas Phycocyanin dari Mikroalga (Spirulina platensik)’, TEKNIK, 33(3), pp. 187-192.

Kant, R. (2012) 'Textile Dyeing Industry an Environmental Hazard’, Journal Natural Science, 4(1), p. 5.

Kartika, B. (1988) Pedoman Uji Inderawi Bahan Pangan. Yogyakarta: UGM : PAU.

Kartina, B., T. Ashar, dan W. H. (2013) 'Karakteristik Pedagang, Sanitasi Pengolahan dan Analisa Kandungan Rhodamin B pada Bumbu Cabai Giling di Pasar Tradisional Kecamatan Medan Baru Tahun 2012', Lingkungan dan Kesehatan Kerja, 1(2), pp. 1-7.

Lawless, T. Harry, H. H. (2010) ‘Sensory Evaluation of Food, Principles and Practice’, Springer. 
Paryanto, A. Purwanto, E. Kwartiningsih, dan E. M. (2012) 'Pembuatan Zat warna Alami dalam Bentuk Serbuk untuk Mendukung Industri Batik di Indonesia’, Jurnal Rekayasa Proses, 6(1), pp. 26-29.

Pranoto, D., M. Purwanto, A. Widiawati, dan R. S. (2017) Pewarna Alami Daun Pepaya(Carica papaya. L) untuk Kain Linen. Universitasy of Brawijaya, Malang, Indonesia.

Pringgenies, D., E. Supriyantini, R. Azizah, R. I. dan O. K. R. (2012) Aplikasi Pewarnaan Bahan Alam Mangrove Untuk Bahan Batik Sebagai Diversifikasi Usaha Di Desa Binaan Kabupaten Semarang. Universitas Diponegoro.

Purnomo, M. A. J. (2004) 'Pewarna Alam sebagai Alternatif Zat Warna yang Ramah Lingkungan', Jurnal Seni Rupa STSI Surakarta, 1(2), p. : 57-61.

Rungruangkitkrai, N. and R. M. (2012) 'Eco-Friendly of Textiles Dyeing and Printing with Natural Dyes'.

Rusmini, R.R.Manullang, D. (2017) 'Kandungan Kimia Serat Kenaf dari Kompos Kulit Udang dengan Pestisida Nabati Keong Mas', Jurnal Hutan Tropis, 5(1). 